\title{
"Obrigado pela associação": as redes híbridas e o festival do amor Hare Krishna.
}

\author{
Victor Hugo Oliveira Silva ${ }^{1}$ \\ Recebido em março de 2021 \\ Aceito em junho de 2021
}

\section{RESUMO}

A devoção, assim como a ciência analisada por Latour (1997) em Vida de Laboratório, pode ser lida como um saber e um viver construído, que depende de muitos atores. Em vez de um experimento - tornado objetivo por inscrições produzidas na interação entre cientistas, aparelhos, papéis, bactérias e neurônios - o serviço devocional (bhakti yoga) é, para estes Hare Krishnas, fundamentado na possibilidade de construção de uma experiência possibilitada pela interação de devotos, instrumentos, Deidades, livros e oferendas. A unidade de análise para esta reflexão será o templo Hare Krishna de Curitiba, campo no qual venho desenvolvendo minha pesquisa de doutorado em sociologia. Esta experiência se apresenta como a inserção em redes heterogêneas que promovem as mediações e associações necessárias para produção da presença inerente à experiência do serviço devocional e ao engajamento a ele relacionado. Nessa perspectiva o templo poderia ser visto como um laboratório, no qual se produzem as circunstâncias necessárias para a vivência da emoção devocional.

Palavras-Chave: Devoção; TAR; Emoções; Hare Krishna; Religião.

\section{“Thanks for association": hybrid networks and the Hare Krishna's Festival of Love}

\begin{abstract}
Devotion, as well as the science analyzed by Latour (1997) in Laboratory Life, can be read as knowledge and a constructed life that depends on many actors. Instead of an experiment - made objective by inscriptions produced in the interaction between scientists, devices, roles, bacteria and neurons devotional service (bhakti yoga) is, for these Hare Krishnas, based on the possibility of building an experience made possible by the interaction of devotees, instruments, Deities, books and offerings. The unit of analysis for this reflection will be the Hare Krishna temple in Curitiba, the field in which I have been developing my doctoral research in sociology. This experience presents itself as an insertion in heterogeneous networks that promote as necessary mediations and associations for the production of the presence inherent to the experience of devotional service and the engagement related to it. From this perspective, the temple could be seen as a laboratory, in which it is specified as necessary for the experience of devotional emotion.
\end{abstract}

Keywords: Devotion; ANT; Emotions; Hare Krishna; Religião.

1 Doutorando em Sociologia, e mestre em Antropologia Social (2016) pela Universidade Federal do Paraná. E-mail: oliveirasilvavictorhugo@gmail.com 
O que quer que você faça / o que quer que você coma / O que quer que você dê / tudo isso deve ser feito como uma oferenda a mim.

Sri Krishna Bhagavan

Esse texto é fruto da minha pesquisa de doutorado em andamento, na qual reflito sobre a relação entre emoção, juventude e devoção nos festivais devocionais realizados pelo movimento Hare Krishna no Sul do Brasil. Com tal propósito tenho elaborado descrições etnográficas a partir de vivências de campo que vêm sendo realizadas ao longo do processo.

Nesse artigo em particular pretendo utilizar a proposta etnográfica ligada a Teoria do Ator Rede para considerar as associações híbridas que emanam desses festivais. Através da vivência conjunta de eventos especiais do ponto de vista dos interlocutores, a intenção é buscar captar experimentos empíricos do pensamento manifestos nos processos que podemos observar a partir da prática.

Nossa unidade de análise para esse experimento reflexivo são os festivais devocionais realizados pelo Templo Hare Krishna de Curitiba, localizado no centro histórico da cidade e fundado em 1983. Ele é parte da ISKCON (International Society for Krishna Consciousness), instituição organizada em Nova Iorque no ano de 1966 por A. C. Bhaktivedanta Swami Prabhupada (1896-1977), mestre espiritual indiano nascido em Calcutá e representante de uma das linhagens vaishnavas ${ }^{2}$ que se desdobram a partir de escrituras que integram o corpus literário dos Vedas, como o Bhagavad-Gita e o Srimad Bhagavatam.

Essa linhagem é a Brahma Madhva Gaudiya Sampradaya. Segue o tipo de vaishnavismo ensinado por Sri Chaitanya Mahaprabhu (1486-1534), tido por seus seguidores como o avatar 3 mais recente de Krishna (a Suprema Personalidade de

\footnotetext{
${ }^{2}$ Termo utilizado para designar, dentro da pluralidade de tradições que se desdobram a partir do corpus literário que compõe a literatura védica, aqueles que consideram Vishnu ou Krishna como a divindade suprema, aquele que é a própria fonte do Brahman (o absoluto em constante expansão) (Flood, 2016).

3 De acordo com o vaishnavismo gaudiya o Ser Supremo faz Seu advento em várias formas e encarnações. Na verdade, "encarnação" não é considera como sendo a palavra apropriada, tendo em vista que significa "aparecer na carne". A pessoa divina faz seu advento em Sua própria forma e não nos elementos ou na carne deste mundo. Devido a isso é que o nome apropriado para essa descida é avatara, que em sânscrito significa 'aquele que desce'. Cada vinda, ou avatara do Senhor, tem uma
} 
Deus). Um dos principais objetivos de sua vinda, tal como observa Silveira (1999) teria sido justamente a divulgação da prática do cantar dos santos nomes de Deus através do maha-mantra Hare Krishna Hare Krishna Krishna Krishna Hare Hare Hare Rama Hare Rama Rama Rama Hare Hare ${ }^{4}$ processo este chamado de Hari Nama Sankirtana (canto congregacional dos santos nomes).

Tal rito sagrado, além de práticas meditativas e de adoração ritualística, confere uma ênfase especial ao canto congregacional do maha-mantra, um tipo de meditação ou prática de yoga coletiva que se dá na forma a procissões de rua, com estandartes e instrumentos em meio à dança e ao canto do maha-mantra, além da distribuição de alimento espiritualizado, oferecido a Krishna.

Assim a realização periódica de festas e festivais, ao mesmo tempo em que funciona como uma forma de prédica (pois abre as portas do templo para os visitantes), pode ser entendida como um ritual fundamental dessa forma de entender o sagrado, pois sua realização possibilita a vivência de valores centrais da comunidade.

A partir disso, e tendo como horizonte respeitar os constructos nativos a respeito dessa experiência, pretendo aqui me orientar a partir das seguintes questões: qual legibilidade compreensiva o uso da Teoria do Ator Rede pode conferir quando toma como objeto uma manifestação religiosa? Essa forma de proceder com o fenômeno pode ser um caminho para considerar tais experiências para além do conceito de representação? Considero que a utilidade de tal empreendimento se encontra no fato de propiciar o acompanhamento da tentativa de uso de uma proposta metodológica que, ao menos em tese, nos possibilitaria trabalhar com a devoção como sendo algo para além da crença.

Tendo em vista que a epistemologia clássica separa o mundo dos enunciados do mundo das coisas e que a TAR - rompendo com esta dinâmica - considera que os enunciados traduzem as coisas, seria possível afirmar que, a partir de um referencial latouriano, conhecimento e crença sejam quase como sinônimos. Isso implica tomar a devoção e as emoções a ela associadas como manifestações, não somente psicológicas

missão específica, mas, primariamente, ajudam a manter o mundo, guiar os seres vivos na vida e atraílos de volta ao domínio espiritual.

${ }^{4}$ Em uma tradução feita por Swami Prabhupada poderia ser lido como 'Ó Senhor, por favor, faça de mim um instrumento do seu amor'. 
ou neuronais, mas como realidades associativas dizem respeito a uma dimensão ontológica possivelmente outra, na qual os participantes são convidados a adentrar através dos festivais.

Trata-se de uma tentativa de romper com o relativismo ao considerar a diferença e partir do princípio de que o mundo (e a ideia de ser nele implicado) não seja algo único. Nesse sentido, o serviço devocional ou bhakti-yoga (ao mesmo tempo em que figura como meta do processo interacional em um festival praticado) é um caminho mediante o qual o conhecimento revelado desta tradição em particular se configura como uma experiência pragmática e performática aos seus adeptos.

Ao descrever e mapear algumas destas redes de associações heterogêneas o intuito é pensar o modo pelo qual elas contribuem na construção de uma verdade tangível (significativa) àqueles que se dispõem ao processo do serviço devocional ou bhakti-yoga - termo pelo qual é designada a prática regulada (pelo mestre e pelas escrituras) de adoração a Krishna, considerado por seus devotos como a Suprema Personalidade de Deus.

Para realizar tal proposta iniciaremos com algumas considerações metodológicas a respeito da teoria do ator rede. Na segunda parte apresentaremos uma descrição etnográfica de um dos festivais, aqui tomado como objeto. Na terceira e última parte traçaremos alguns paralelos entre a metodologia apresentada e os dados produzidos pela descrição.

\section{Elementos para constituição das redes: considerações metodológicas}

Podemos dizer que o conceito de rede é já antigo na sociologia e nas ciências sociais. Em um de seus usos mais notáveis Norbert Elias (1994), ao apresentar o social como uma rede de relações de interdependência, buscava dissolver a estagnante dicotomia entre indivíduo e sociedade. Bruno Latour (2012), por sua vez, reinventou o uso desse conceito para implodir a própria ideia do social vendo esta ferramenta analítica como uma forma de dissolver outra dicotomia ainda mais profunda e, segundo ele, definidora daquilo que veio a chamar de constituição moderna, a polarização entre natureza e cultura (LATOUR, 2010). 
Assim, diferentemente do uso feito por Elias, as redes na teoria latouriana incluem elementos humanos e não humanos, sendo úteis para compreender a agência dos objetos; tendo em vista que a própria capacidade de agência é entendida como estando distribuída na rede, não sendo um atributo somente humano, mas do próprio agenciamento.

Segundo Latour (2012), nessa perspectiva a rede é uma associação momentânea que tem como finalidade agregar e produzir novas relações. Ela se faz e se desfaz gerando outras. Essa definição torna possível pensarmos o próprio Festival Hare Krishna como uma rede que, sendo temporária e heterogênea, busca produzir experiências através de associações que visam inserir e integrar a pessoa na prática do serviço devocional às Deidades, formas adoráveis da pessoa divina que se encontram instaladas no templo onde ocorre o festival.

Segundo Sá Cardoso (2015) a TAR coloca os veículos da individualidade nos subjetivadores, nas conexões dos elementos de um social reticular, chamados actantes, sendo este um conceito criado no intuito de diminuir o peso semântico de um ator subjetivo humano em prol de uma construção híbrida.

Tal postura metodológica se encontra fundamentada na transição daquilo que Latour chamou de sociologia do social (de inspiração durkheiminiana e que assim vê o social como um todo exterior, objetivo e coercitivo) para uma sociologia das associações (LATOUR, 2012). Nessa nova perspectiva, inspirada por Gabriel Tarde, o social não se explicaria pelo social, tal como proposto por Durkheim (como uma dimensão ontológica particular), mas é visto como um movimento peculiar de reassociação e reagregação, algo que acaba por redefinir a sociologia como um traçado de associações, ou "um tipo de conexão entre coisas que não são em si mesmas sociais" (LATOUR 2012 p.23). Tal como colocam Gonzales e Baum (2013), a pesquisa realizada nestes moldes se torna uma

viagem investigativa dos rastros que os movimentos em associações vão deixando em marcas conceituais, unidades ontológicas, crenças e artefatos culturais, artísticos, científicos, etc.. que também estão em contínua dispersão para novas associações e, por conseguinte, outras 'estabilizações'. Este social (associado) nunca se deixa apreender. Ele não é visível nem substantivado, e justamente por isso, se compõe de elementos que não podem ser chamados de elementos sociais. Pode sim, agregar elementos políticos, econômicos, físicos, 
biológicos, químicos, tecnológicos, linguísticos, etc... mas, nunca, elementos sociais compondo o 'social'. O 'social' não se explica pelo 'social', o que seria uma redundância estéril (GONZALES; BAUM, 2013, p. 150).

No intuito de seguir estes movimentos e realizar a viagem investigativa acima comentada, Latour (2012) afirmou que é necessário seguir os atores no curso de suas associações, tornando plana a sequência de associações e tomando o cuidado de não buscar explicar o social como um conjunto de conceitos interligados. Neste percurso investigativo se faz então necessário localizar alguns sinalizadores que indicam como seguir as conexões feitas pelos agentes em ação, o que faz com que a primeira incumbência do pesquisador seja "retomar a tarefa de descobrir associações".

\section{Experimento descritivo - Festival de Domingo no Templo Hare Krishna de Curitiba}

Era domingo, o final de tarde movimentava o centro histórico de Curitiba, alguém que no céu reparasse poderia lembrar-se de um verso do velho Leminski: "O amor é um elo/ entre o azul e o amarelo" e - depois de meditar um pouco nas nuvens e seus contrastes, na luz densa e amarelada (quase tangível) que aviva a cor tanto das pedras quanto das paredes - seguir.

Reuniam-se os restos da feirinha (que já foi hippie e hoje é de tudo um pouco, chique para alguns, cansativa para outros). Os ecos de um rebuliço ainda se dissolvendo se espalhavam pelo Largo da Ordem, sua sutil desordem se arrumava e as pessoas aglomeravam-se nas mesas sob a calçada, descendo ou subindo a Trajano Reis em torno de tragos e violão ou ainda passando em frente à Igreja do Rosário. Pessoas sentadas namorando, bêbados se deslocando, turistas tirando fotos, feirantes buscando o ganha pão.

Descendo pela rua Duque de Caxias, exatamente na esquina com a Treze de Maio, número 76, por volta das cinco era possível ouvir ecoando de longe, reverberando entre os prédios e ruas vazias, não somente o som que fazem por vezes no Vila Bambu ou na roda de choro do Tragos Largos, mas também um tilintar sibilino e rítmico que, na medida em que nos aproximamos ia ganhando contornos melódicos, 
mântricos, e que, já na porta do Templo, se manifesta também como um som aromático.

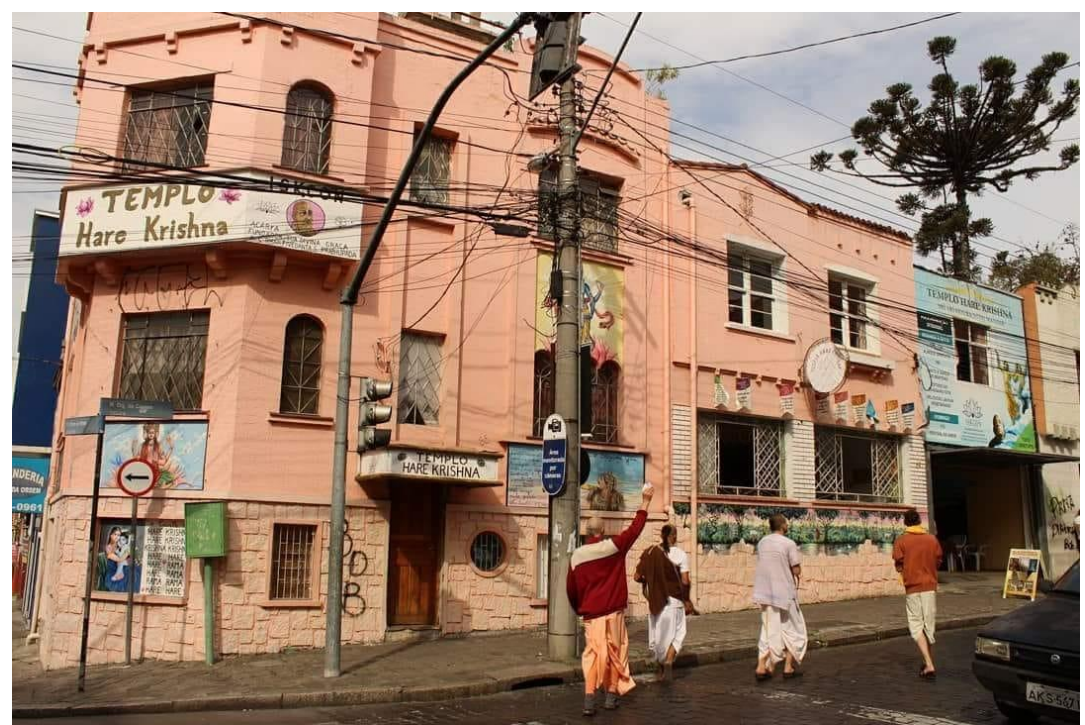

Figura 1: $\mathrm{O}$ templo Hare Krishna de Curitiba. Fonte: registro do autor.

Hare Krishna Hare Krishna Krishna Krishna Hare Hare Hare Rama Hare Rama Rama Rama Hare Hare. A melodia ondulava, variava, intensificava-se e suavizava como fumaça de incenso pairando no ar pra subir. E assim como de longe se ouvia o som, de fora também se percebia incensos de sândalo, de flores do Nepal (tal como aquele já bem difundido 'nag champa') os quais, a depender da situação, podem estar se misturando com o aroma de coentro e cominho sendo fritos no ghee para o preparo da oferenda.

Em frente à porta de alumínio da entrada, esperando após ter tocado a campainha, era possível ainda observar o açafrão predominante das paredes e também os belíssimos murais pintados à mão que embelezavam e conferiam um aspecto exótico e não convencional à arquitetura do local.

Estes murais, no linguajar dos devotos, apresentam janelas para o mundo transcendental. São reproduções de pinturas presentes nos livros que propagam a filosofia vaishnava. Elas tematizam os intercâmbios amorosos de Krishna (considerado como a Suprema Personalidade de Deus) com seus devotos íntimos, tais como sua Mãe, seus amigos e as donzelas de Vrindavana - cidade mítica, local sagrado e 
histórico, esta cidade é para os devotos de Krishna o local por excelência no qual se vivencia o amor por Deus da forma mais intensa, pura e pessoal possível.

Do lado esquerdo da porta em frente a qual aguardava para entrar no Templo se encontrava, sob o fundo açafroado da parede, a reprodução de uma cena idílica às margens do rio Yamuna numa tarde de outono. Ali se encontram perdidas em meio à floresta com seus saris coloridos as jovens vaqueirinhas de Vrindavana dançando com Krishna em suas múltiplas expansões. Ao lado desta pintura, também na parede frontal encontrava-se uma cena da conversa entre Krishna e seu discípulo e amigo Arjuna. Junto a ela vimos a transcrição de um dos versos desse que é um dos mais importantes diálogos da filosofia védica como um todo, o Bhagavad-Gita, ou, tal como foi traduzido por Rogério Duarte, 'Canção do Divino Mestre'.

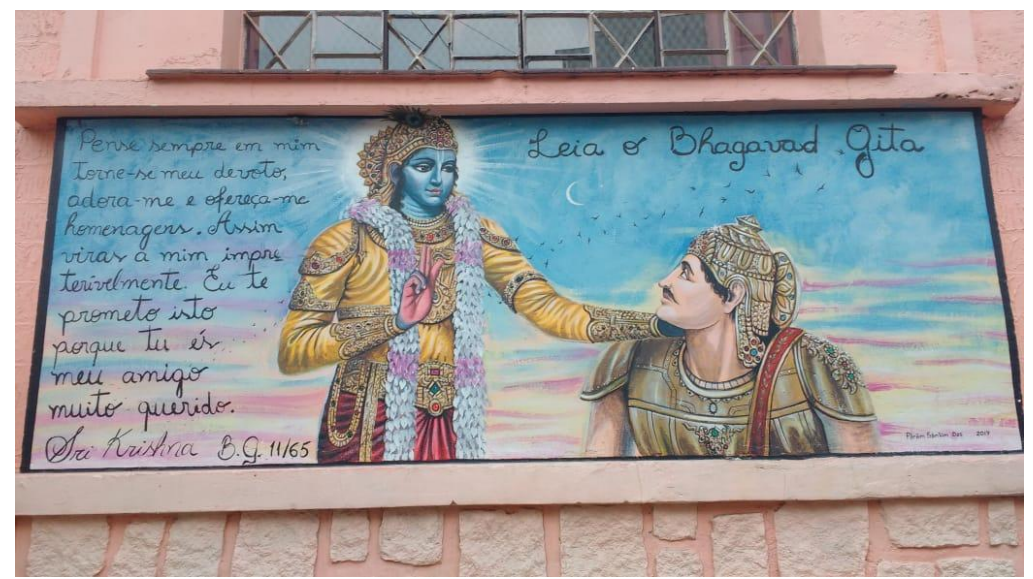

Figura 2: Mural de entrada. Fonte: registro do autor.

O verso escolhido para estar ali transcrito, inscrito, gravado a letra corrida em tinta preta sob o fundo azulado e multicolorido na parede do Templo - juntamente com a cena do diálogo - serviu como uma epígrafe para o próprio festival ao qual se estava prestes a entrar. Serviu ainda, buscando não congelar a imagem (LATOUR,2004) como uma espécie de resumo das atividades que ali dentro se desdobram: "Pense sempre em mim, torna-se meu devoto, adora-me e ofereça-me homenagens. Assim virás a mim impreterivelmente. Eu te prometo isto porque tu és meu amigo muito querido".

Talvez você tenha recebido um convitinho enquanto sorria ao vê-los passar mais cedo, cantando e dançando alegremente na feirinha com seus instrumentos, 
roupas esvoaçantes-coloridas e estandartes, talvez você tenha vindo pra almoçar ao meio dia no restaurante dos "Hares" e ficou sabendo que mais tarde haveria um festival, talvez você tenha comprado um livro na rua XV, num ônibus ou em um farol ou ainda, depois de uma noite em claro, foi pegar o 'rango' vegetariano e gratuito que se distribui ali durante a semana e ficou curioso para, num domingo desses, depois de muito pensar, voltar lá no templo.

São muitas as associações que podem levar alguém a participar do Festival do Amor. Esse foi o nome que A. C. Bhaktivedanta Swami Prabhupada, o fundador da Sociedade Internacional para Consciência de Krishna (ISKCON - instituição à qual este templo em questão faz parte) deu ao evento através do qual ele passou a apresentar a consciência de Krishna e a prática da Bhakti-Yoga aos jovens de Nova York na segunda metade da década de 1960. Nesse encontro ocorre, tal como presente nos convitinhos distribuídos pelos devotos nas ruas: Canto de Mantras, palestra filosófica e jantar vegetariano, tudo gratuito.

Em cada centro de nossa instituição, a ISKCON, organizamos um banquete de
amor todos os domingos, e quando realmente vemos pessoas virem ao nosso
centro, cantar, dançar, tomar prasadam, ficar exultantes e comprar livros,
sabemos que certamente Sri Caitanya Mahaprabhu está sempre presente em
tais atividades transcendentais, e Ele está muito satisfeito. Portanto, os
membros da ISKCON devem aumentar esse movimento cada vez mais, de
acordo com os princípios que estamos tentando executar atualmente. Sri
Caitanya Mahaprabhu, assim sendo satisfeito, olhará sorrateiramente para
eles, concedendo Seu favor, e o movimento será bem sucedido.
(PRABHUPADA, 1975, p. 341).

Pela passagem acima percebemos que festival tem para os devotos que o realizam um sentido missionário e ao mesmo tempo mítico-profético. Sua realização, ao ser bem sucedida em atrair pessoas para cantar, dançar e banquetear tendo Krishna como centro, se manifesta como a efetivação do propósito específico do último avatar de Krishna, Sri Caitanya Mahaprabhu.

Considera-se que a vinda de um avatara da personalidade de Deus sempre tem objetivo característico, ligado ao momento no qual ela se manifesta e às prescrições escriturais ligadas ao seu aparecimento. No caso de Sri Caitanya, considerado o avatar 
Dourado, seu propósito5, tal como afirma Steven Rosen (2017), é propagar da maneira o mais ampla possível o cantar dos nomes de Deus, através do maha mantra Hare Krishna, como o processo de auto-realização mais eficaz para a era presente.

Quando cheguei ao Templo, no final de tarde do dia 22 de julho de 2018, um amigo antigo de longa data, chamado Ananta Lila Madhva Das - um devoto eletricista que, apesar de não morar no templo, quase sempre ajudava na preparação do festival de domingo - abriu a porta e sorriu ao me ver chegar junto com minha esposa e nossas duas filhas. Tal como muitas vezes ao longo desses últimos anos estava novamente no Festival de Domingo, mas, desta vez, com a atenção voltada para diferentes elementos, conexões, fluxos e detalhes que pudessem ser úteis no processo de descrição e reflexão acadêmica ao qual, enquanto pesquisador, nesse momento da vida me proponho.

Trocamos reverências, reclinando nosso corpo, tocando nossas cabeças no chão e cantando em voz meio sussurrada e velocidade acelerada o mantra de saudação entre os devotos: "Vancha-kalpatarubhyas ca/ krpa-sindhubhya eva ca/ patitanam pavanebhyo /vaisnavebhyo namo namah", cuja tradução é: "Ofereço minhas respeitosas reverências a todos os devotos Vaisnavas do Senhor, que estão cheios de compaixão pelas almas caídas e que são exatamente como árvores dos desejos, podendo satisfazer os desejos de todos".

Depois disso atravessei o salão de baixo, espaço utilizado como refeitório e também como restaurante aos domingos. Deixei meu calçado no local apropriado. Subi as escadas rumo à sala do altar, espaço no qual se desenrola a maior parte do festival. Ao menos para os visitantes, tendo em vista que os devotos ficam num vai-e-vem constante entre os diversos espaços do templo - especialmente a cozinha - para possibilitar o acontecimento das atividades do encontro.

No topo da escada ao lado esquerdo existe um pequeno sino de cobre, tocado pelos devotos quando adentram a sala do templo. Neste andar superior se encontra,

\footnotetext{
${ }_{5}$ Prthivite ache yata nagaradi grama - Sarvatra pracara haibe mora nama "Em todas as cidades e aldeias, o cantar do Meu nome será ouvido". [Sri Caitanya-bhagavata (Antya-khanda 4.126). (PRABHUPADA, 1975, p. 354)]
} 
além do altar onde ficam as Deidades, uma cozinha destinada especificamente ao preparo das oferendas, na qual se pode entrar somente com 'roupa devocional' 6 .

O salão é relativamente amplo, sendo dividido em dois níveis - resultado de uma recente ampliação destinada a aumentar o espaço para receber os visitantes. Suas paredes eram pintadas em uma tonalidade amarela, conferindo leveza ao ambiente. As paredes eram decoradas com quadros que apresentavam além dos passatempos de Krishna frases de Prabhupada acerca da importância da distribuição de livros.

Do lado direito deste espaço estava o altar, o qual no início do festival se encontrava com as cortinas fechadas e, do lado esquerdo, uma Murti (forma adorável) do Acarya-Fundador da ISKCON, A.C. Bhaktivedanta Swami Prabhupada.

Quando cheguei ao templo, por volta das cinco da tarde, a programação já havia se iniciado e alguns devotos cantavam o mantra Hare Krishna com tambores, címbalos e um instrumento de fole e teclas chamado harmonium. Este momento do festival, uma espécie de introdução, é chamado de bhajana, termo sânscrito que significa adoração e é utilizado para se referir ao canto congregacional realizado de forma intimista, quando os praticantes se encontram sentados no chão. Com melodias suaves e de matriz oriental o mantra era repetido diversas vezes, a pessoa responsável por liderar o canto propôs uma melodia que era em seguida reproduzida pelos presentes, os quais eram assim estimulados a também cantarem o mantra.

O canto, especialmente do maha-mantra Hare Krishna, é o centro da vida devocional. Sendo definido como transcendental por ser igual a Krishna (Deus), considera-se que pelo cantar constante desse mantra é possível obter a purificação da consciência através da qual o praticante pode realizar sua natureza espiritual bem como seu eterno relacionamento amoroso com Deus (VALERA, 2015). Desse modo o som deste mantra se faz presente em todos diferentes momentos do festival.

Após o término do bhajana um dos devotos convidou os presentes a ficarem de pé e direcionados à murti de Swami Prabhupada para realização da próxima etapa: o

\footnotetext{
${ }^{6}$ Vestes simples tradicionalmente utilizadas para a prática do serviço devocional a Krishna. Os homens usam o dhoti (um pano longo sem costuras amarrado com uma técnica específica ao redor da cintura) e kurta (uma camisa longa) e as mulheres usam saree (um pano que ao ser amarrado no corpo, serve como saia e véu)
} 
Guru-Puja (adoração ao mestre espiritual). Tal como na fase anterior os homens ficavam de um lado e as mulheres de outro, mas agora em pé.

Essa forma que estava prestes a ser adorada apresentava traços intensamente realistas. Tendo o mesmo tamanho de uma forma humana, o mestre se encontrava sentado de pernas cruzadas em um assento de madeira e almofadado, com uma pele morena, olhar sereno, rosto levemente enrugado, testa decorada com tilaka e vestes açafroadas como se ele estivesse de fato ali, observando tudo que se passava.

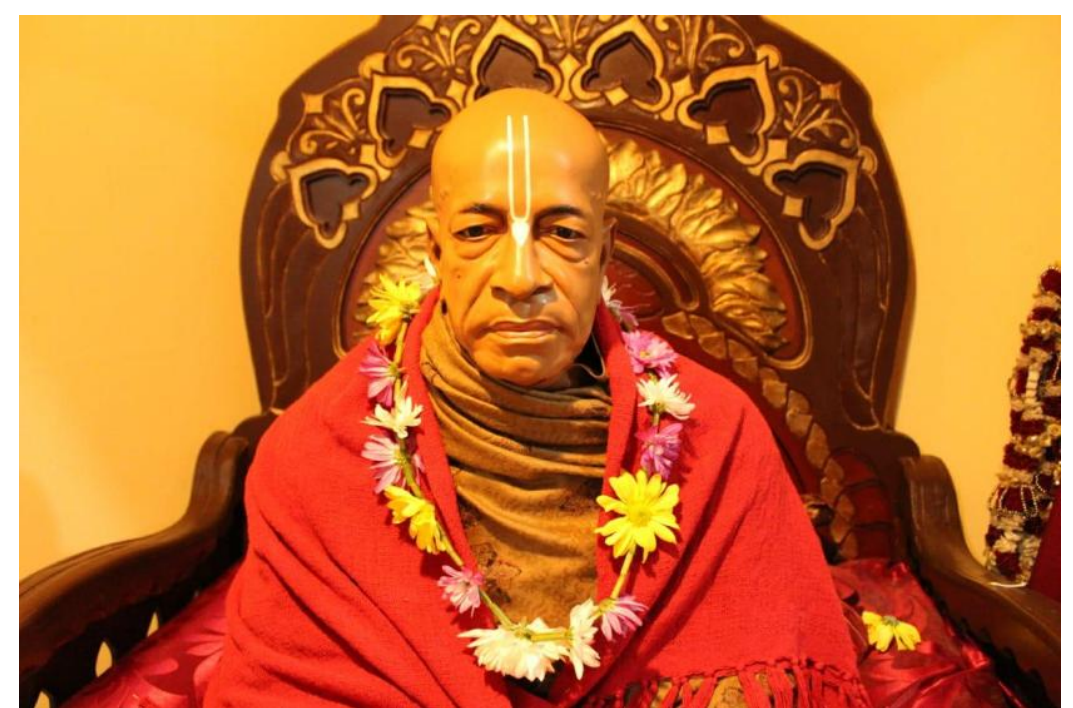

Figura 3: forma adorável de A. C. Bhaktivedanta Swami Prabhupada. Fonte: registro do autor.

Em frente à forma adorável do mestre foi colocado um banco sobre o qual estava um prato dourado contendo diferentes objetos que seriam utilizados na adoração. Os presentes, agora em pé e dançando, já reunidos em frente à forma de Prabhupada começaram a cantar em louvor ao mestre. Um dos devotos se aproximou do prato de adoração e, após prestar reverência e utilizar um pequeno recipiente com água para se descontaminar pingando gotas sobre a mão e entoando mantras com diferentes nomes de Krishna, pegou um grande búzio - o qual foi também descontaminado com algumas gotas de água - e o fez soar três vezes assoprando-o com força.

${ }^{7}$ Tipo de argila oriunda de rios sagrados indianos como o Ganges e o Yamuna, usada diariamente pelos devotos para marcar seu corpo em partes específicas com um símbolo vaishnava. Cada local passado tem um mantra específico para ser entoado, os quais contêm diferentes nomes de Krishna. 
Esse som marca o início do aratik, termo sânscrito utilizado para se referir à cerimônia na qual são oferecidos os quatro elementos a uma pessoa que, de modo geral, é o mestre espiritual ou a própria divindade. Esse processo de oferenda tem, segundo Rosen (2014), um duplo propósito: ao mesmo tempo em que busca fornecer prazer a pessoa que está sendo adorada, visa proporcionar purificação àqueles que desfrutam destes mesmos elementos após eles se tornarem prasadam, ou, misericórdia. Considera-se que, ao serem oferecidos, esses elementos deixam de ser materiais, pois foram conectados à transcendência mediante o processo concreto de adoração. Mediante esse ritual eles se tornariam também espiritualizados, de modo que aqueles que entram em contato com esses resíduos também se espiritualizariam, obtendo assim purificação da consciência.

Os elementos a serem oferecidos encontravam-se presentes no prato dourado utilizado na cerimônia, chamado de 'prato de aratik'. Sobre ele, foram colocadas uma lamparina feita de algodão e ghee (fogo), um incenso (terra), um recipiente contendo água, uma flor e um pequeno lenço. O elemento ar é representado por um objeto chamado camara, uma espécie de abano utilizado para refrescar a pessoa adorada, que se encontra pendurado ao lado do assento do mestre.

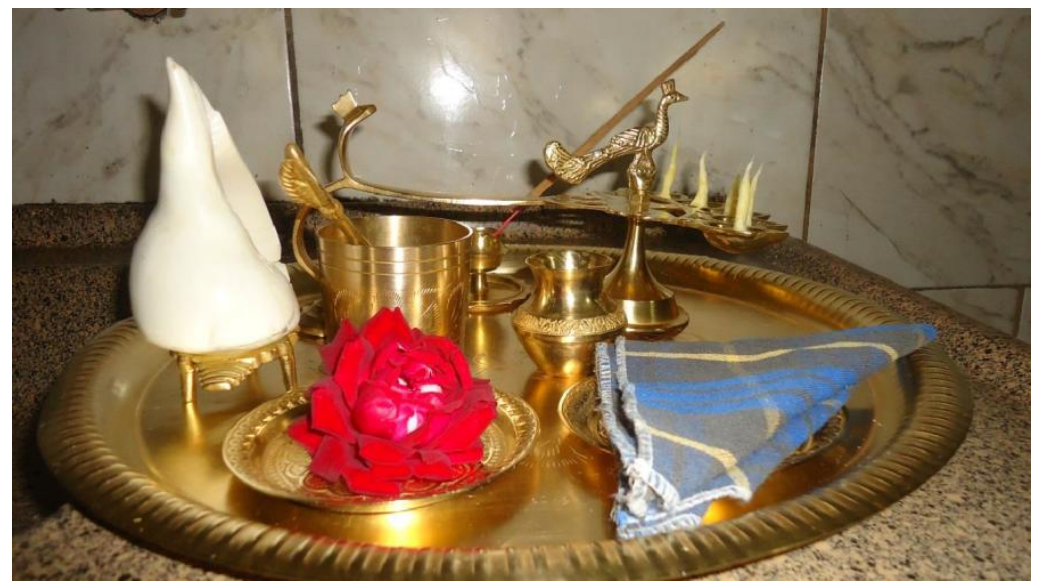

Figura 4: Prato de Aratik. Fonte: registro do autor.

No ritual cada um desses objetos foi oferecido da seguinte forma: enquanto fazia trinar um sino com a mão esquerda, o devoto pegava, com a mão direita, cada um dos elementos e, meditando naquele que estava recebendo a adoração, oferecia um elemento de cada vez fazendo sete voltas circulares em direção ao ser adorado. 
Importante notar que antes de ser ofertado cada elemento era purificado com uma gota de água proveniente de um pequeno recipiente, também presente no prato, chamado panca-patra. Após ser oferecido, o elemento agora espiritualizado foi passado para as mãos de outro devoto que se responsabilizou por oferecê-lo a cada um dos aos outros presentes, os quais se encontravam dançando ao som da mrdanga (tambor de barro com duas peles) e das kartalas (címbalos de mão) enquanto entoavam uma canção em sânscrito em homenagem ao mestre.

Já desfrutando a misericórdia daquilo que foi ofertado ao mestre, os participantes, enquanto cantavam e dançavam, sentiam o aroma do incenso e recebiam das mãos de um devoto ou devota uma flor para cheirar, gotas de água sobre a cabeça e uma lamparina de fogo sobre a qual eram instruídos a passar a mão, levando-a em seguida à cabeça ou ao coração.

Ao terminar a oferenda dos elementos, ressoando novamente o búzio, o devoto que estava oferecendo prostrou-se em reverência diante do mestre e juntou-se aos outros devotos e visitantes que cantavam. Nesse momento o canto era mais entusiasmado e efusivo sendo que, após a canção especificamente direcionada ao mestre, mais uma vez os presentes cantaram o maha-mantra Hare Krishna. Formaramse então duas rodas, uma com as mulheres e outra com os homens, enquanto os presentes dançavam e pulavam estimulados pelos devotos e devotas, que têm na prática da dança uma das formas de expressar sua alegria devocional. Ao final todos prestaram reverência, prostrando o corpo e tocando sua cabeça no chão enquanto murmuravam um mantra de saudação ao seu mestre.

Após o final canto, os presentes, agora sentados - sendo que alguns estavam inclusive suados e com a respiração intensificada devido à dança - ouviram a tradução ${ }^{8}$

\footnotetext{
8“Os pés de lótus de nosso mestre espiritual são o único caminho pelo qual podemos alcançar o serviço devocional puro. Eu me prostro perante os seus pés de lótus com grande respeito e veneração. Por sua graça uma pessoa pode cruzar o oceano de sofrimento material e alcançar assim a misericórdia de Krishna. Meu único desejo é ter a minha consciência purificada pelas palavras que emanam de sua boca de lótus. O apego aos seus pés de lótus é a perfeição que satisfaz todos os desejos; ele abre os meus olhos obscurecidos e enche o meu coração com conhecimento transcendental. Ele é meu Senhor, nascimento após nascimento. Dele prema extático emana, por ele a ignorância é destruída. As escrituras védicas cantam seu caráter; nosso mestre espiritual é um oceano de misericórdia, amigo dos pobres, senhor e amo dos devotos. Ó mestre, sê misericordioso comigo e concede-me a sombra de seus pés de lótus. A sua fama se espalha por todos os três mundos e nós caímos aos seus pés de lótus".
} 
da canção previamente entoada enquanto iam recebendo pequenas quantidades de pétalas de rosa, as quais foram então oferecidas por cada um dos presentes aos pés do mestre.

Estes pés são personificados por um quadrado bronzeado, colocado no chão à frente da forma adorável. Sobre este se encontravam gravadas as marcas dos pés do mestre que, ao final da cerimônia, terminaram cobertas por pétalas.

Quanto a originalidade da peça em questão, ou seja, se Bhaktivedanta Swami Prabhupada teria realmente feito as marcas de seus pés naquela peça ou se ela seria uma réplica, um devoto chamado Ekacakra Pran Das certo dia me contou: "Em um determinado momento me surgiu essa dúvida e, certa vez, perguntei a um discípulo direto de Prabhupada o que ele pensava a respeito, e ele me deu uma resposta muito transcendental, dizendo que não importava a resposta em si, só de pensarmos nessa possibilidade aquela plataforma de bronze onde se encontram registrados os pés do mestre já se torna transcendental”.

Enquanto algumas pessoas ainda estavam finalizando a oferenda das pétalas, lançadas por sobre essa plataforma, um dos devotos anunciou a próxima etapa do programa, uma palestra acerca do Bhagavad-Gita, a principal escritura dos devotos de Krishna. O devoto responsável por proferir a palestra, chamado Ekendra Das, sentouse em um assento de madeira almofadado chamado vyasasana (termo que significa assento do representante de Vyasa -aquele que transcreveu os Vedas). O assento ficava no lado oposto ao que se encontrava situado o altar, que continuava com as cortinas fechadas. Os homens foram convidados a se sentarem do lado direito e as mulheres do lado esquerdo, para acompanharem este momento mais silencioso e introspectivo do festival.

A palestra, transmitida ao vivo na página do templo no facebook, só ocorreu após mais uma sessão de canto: primeiro de uma canção chamada Jay Radha Madhva, do mantra Hare Krishna e, finalmente do mantra Om Namo Bhagavate Vasudevaya99. O verso da escritura a ser comentada foi escrito em um quadro negro, de modo que os presentes pudessem acompanhar a entoação em sânscrito - considerada pelos devotos

\footnotetext{
9 “Ofereço minhas humildes e respeitosas reverências a onipresente Suprema Personalidade de Deus”.
} 
como sendo uma língua capaz de produzir vibrações auspiciosas para o desenvolvimento de conhecimento espiritual.

Ao final da palestra, que tratava em linhas gerais acerca do modo pelo qual o desenvolvimento da consciência espiritual pode levar a paz tanto individual quanto coletiva, soou novamente o búzio, ao longo de três potentes e ressoantes oportunidades. As pessoas foram então convidadas a se levantar e virar em direção ao altar.

Havia uma expectativa no ar, devido ao fato de este ser o primeiro domingo no qual as Deidades iriam se manifestar apresentando sua pintura nova. As Deidades presentes no templo de Curitiba vieram, segundo me relatou um devoto antigo, dos Estados Unidos, país no qual foi fundada, por Swami Prabhupada, a Sociedade Internacional para Consciência de Krishna (ISKCON) em 1966. Elas foram confeccionadas a partir de uma escultura em mármore vinda da Índia, a partir da qual foram feitas duas réplicas, sendo que uma delas é a dupla de Deidades que vieram para Curitiba.

Segundo a tradição vaishnava a Suprema Personalidade de Deus passa a habitar pessoalmente a Deidade somente a partir de um ritual de instalação, no qual ele é convidado a se manifestar e a estar presente nesta forma adorável em específico. Esse ritual foi realizado em Curitiba na década de 8o. Desde então as Deidades residiram em diversas casas - tendo em vista o fato de o templo estar localizado em uma casa alugada. Uma das atividades periódicas de manutenção e cuidado para com as estas formas adoráveis (murti) é a pintura periódica das mesmas. Ela deve ser realizada por um devoto, preferencialmente um brâmane ${ }^{10}$.

No dia em que fui ao templo as Deidades haviam acabado de receber uma nova pintura, o que dava a elas um brilho novo e especial. Este festival de domingo foi o primeiro em que elas foram contempladas pela comunidade, algo que causou certa expectativa entre os presentes.

\footnotetext{
1o Os devotos considerados brahmanes são aqueles que receberam duas iniciações, podendo assim meditar o matra gayatri e usar o cordão sagrado. É simultaneamente um status de pureza e, consequentemente, hierárquico dentro da estrutura organizacional do grupo
} 
Após o som do búzio a cortina, ritmando o tempo da festa e redirecionando molduras, foi aberta e todos se prostraram esticando o corpo no chão em um tipo de reverência chamada dandavats (que significa literalmente, como uma vara). Dentro do altar havia um devoto que, com os mesmos itens representando os elementos fundamentais, realizava a cerimônia de oferenda (aratik) mas, nesta ocasião, de uma forma mais demorada tendo em vista que cada elemento (incenso, lamparina, flor, água, lenço e camara) foi ofertado a cada uma das diversas personalidades divinas e mestres presentes no altar.

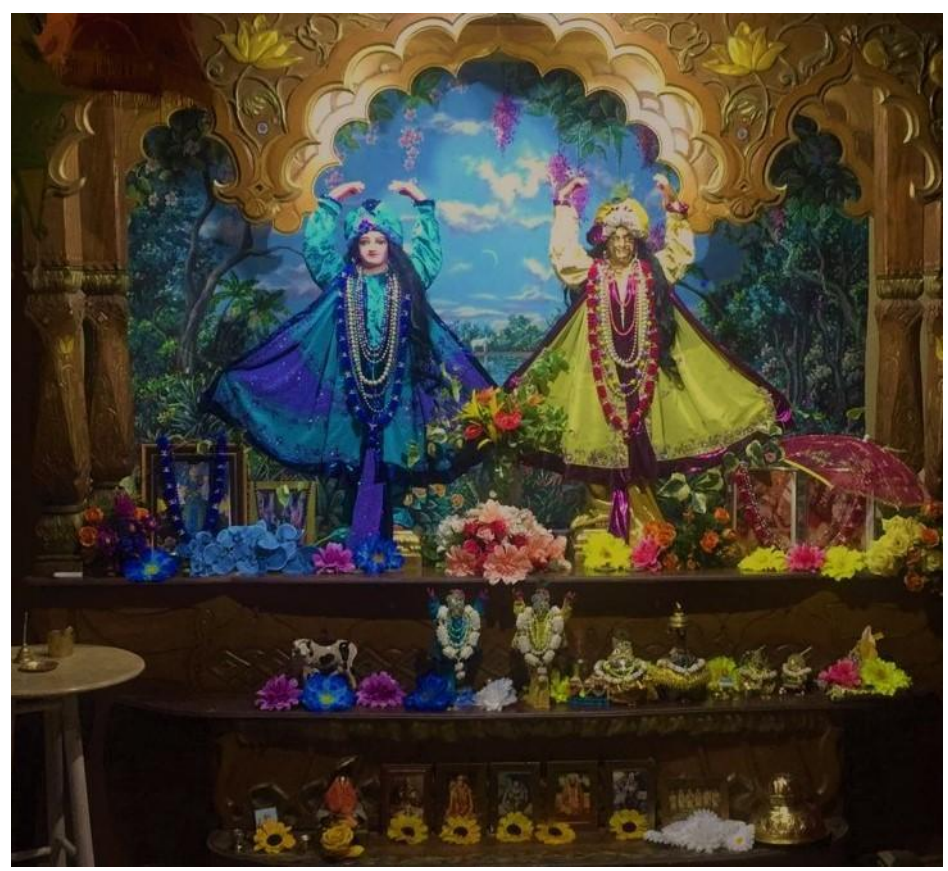

Figura 5: $\mathrm{O}$ altar. Fonte: registro do autor.

Ao fundo do altar se podia ver a pintura de árvores e céu azul, compondo um cenário extremamente colorido e idílico emoldurado por uma madeira entalhada. As deidades estavam decoradas com roupas azuis e amarelas, flores e jóias. Ao todo elas são seis, sendo que duas destas são as principais, a saber, Sri Caitanya Mahaprabhu e Sri Nityananda -conhecidos como Goura e Nitai - ficam no centro do altar, com aproximadamente um metro de altura. Estão presentes no altar também deidades pequenas de Goura e Nitai (as deidades chamadas "funcionais"), com cerca de vinte centímetros e outras quatro deidades, a saber, Mukunda (nome que foi dado à 
Shalagrama-shila ${ }^{11}$, Laksmi, Nrsimhadeva, e Prahlada Maharaj, todas pequenas, com no máximo dez centímetros. Laksmi é tão pequenininha, com menos de cinco centímetros, que só chegando bem perto do altar se podia notá-la

Além das deidades propriamente ditas, estavam no altar também algumas outras imagens, como a de Radharani (a forma feminina de Deus), a forma de Tulasi no mundo espiritual (uma devota que na Terra se manifesta como um arbusto sagrado, conhecido como manjericão santo), um búzio chamado de Laksmi-Narayana, e uma imagem do panca-tattva, que, bem como as demais imagens citadas, são decorados com colares diariamente. Na plataforma mais baixa do altar ficava uma forma de Swami Prabhupada, bem como os quadros de Sua Santidade Jayapataka Swami, Srila Bhaktivedanta Swami Prabhupada, Srila Bhaktisidanta Sarasvati Thakur, Srila Bhaktivinoda Thakur, Srila Goura Kishora Babaji, Srila Jaganatha Babaji, e os Seis Goswamis de Vrindavan -discípulos diretos de Sri Caitanya Mahaprabhu. Estes quadros são dos mestres da linha de sucessão discipular do vaishnavismo gaudiya.

Quando as cortinas do altar se abriram, exibindo as per sonalidades divinas que ali residem, após as devidas reverências, os devotos entoaram uma canção especificamente destinada ao momento de adoração às Deidades de Chaitanya e Nitiananda. Assim como na adoração ao mestre, mais uma vez e de modo ainda mais entusiasmado foi cantado o maha-mantra Hare Krishna, ao som das mrdangas e kartalas $^{12}$ devidamente acompanhados por passos de uma dança circular seguindo o ritmo pulsante ternário dos instrumentos.

Tal como me relatou um dos presentes, a alegria dos devotos no momento do kirtana (canto com dança) é vista como um sintoma de que as Deidades ficaram felizes com a nova pintura. Como Krishna reside no coração de todos na forma de superalma

\footnotetext{
${ }^{11}$ É uma negra pedra esférica considerada sagrada, proveniente do rio Gandaki, Himalaia. Em escrituras como o Skanda Purana afirma-se que "uma Shalagrama Shila Genuína é uma manifestação direta do Senhor Vishnu e não requer nenhuma instalação." Apesar de se manifestar externamente como pedra, a Shalagrama Shila é considerada uma jóia preciosa e sagrada, sendo enfeitada e adorada como uma deidade.

${ }^{12}$ Como me relatou um devoto chamado Murari Das, o som estridente e sibilino das karatalas atua no sétimo chakra de modo que as janelas da visão se abram para perceber a beleza espiritual que reside no altar. Já a Mrdanga, o tambor de barro, seria uma expansão da forma feminina de Balaram (o irmão de Krishna e sua primeira expansão plenária) que se manifesta como o coração do kirtana para acompanhar Sri Caitanya Mahaprabhu em seus passatempos.
} 
(paramatma) satisfazê-lo pessoalmente através do serviço à Deidade, vista como uma pessoa e não como uma representação, produz uma alegria interna também nos devotos, a qual se manifesta na forma do canto e da dança.

Após o término da cerimônia e das devidas reverências, um dos devotos residentes nos templo na época, chamado Nitai Ulas Das, pediu a palavra e fez um agradecimento, em nome de toda comunidade, ao devoto responsável pela pintura, presenteando-o com alguns livros, devidamente envoltos em um pacote de presente. $\mathrm{O}$ pintor, chamado Nrsimha Bhagavan Das saiu de dentro do altar, pois ali havia sido o responsável pela realização da cerimônia de aratik, e, de forma discreta, recebeu os presentes agradecendo com as mãos postas em sinal de reverência.

Antes daquela que é em geral a última parte do festival, houve um momento no qual um dos devotos leu, em frente ao altar, os resultados da Maratona de Julho de distribuição dos livros de Srila Prabhupada. Essa lista foi lida como forma de oferecer o resultado dos livros distribuídos para as Deidades de Sri Caitanya e Nitiananda, os precursores do Movimento de Sankirtana (Canto congregacional dos Santos Nomes). Era uma lista grande com mais de cinquenta nomes de devotos e devotas que durante o mês que terminava haviam se dedicado a realizar esta atividade missionária. A leitura da lista pode ter sido encarada de modo um pouco entediante por quem ia ao templo pela primeira vez mas, para os devotos presentes era uma grande alegria. Ao final da leitura de cada nome, dos livros distribuídos e dos pontos feitos ouvia-se o grito de 'Jay', termo sânscrito que significa 'vitória'.

Finalizando o festival foi servido um jantar vegetariano, o qual era também prasadam, pois havia sido previamente oferecido às Deidades. Nesse momento ocorreu uma confraternização na qual os devotos aproveitam para tirar as dúvidas e pregar para os visitantes.

\section{O Festival e a mediação pelo som}

Buscando aplicar os princípios de uma metodologia que tenha o conceito de rede como horizonte, percebi que diversos objetos ou, melhor dizendo, actantes estabelecem uma mediação entre espaços, indo de um pólo considerado impuro e 
material (a rua, ou o lado de fora do templo) para um espaço interior, definido como puro (purificador) e transcendental (o altar no qual é possível ver as Deidades).

O festival e as atividades de serviço devocional que emanam a partir das Deidades (como distribuição de livros e de alimento espiritualizado) são vistos pelos devotos como uma das formas pelas quais se concretiza a profecia de Sri Chaitanya, presente pessoalmente no templo através da forma da Deidade e nas instruções do mestre espiritual. Assim, o festival enquanto uma rede dispõe linhas de associações que ao se abrirem para a cidade e para os visitantes busca colocá-los em contato com elementos passíveis de promover uma espiritualização, ou, purificação, ao associá-los de algum modo ao processo de serviço devocional.

Essa ideia, segundo a qual o festival pode ser entendido como uma rede que visa produzir a experiência da presença da devoção a Krishna (ou a purificação dos participantes), pode ainda ser aprofundada se considerarmos o termo sânscrito para a palavra festival, utsava. Segundo Rosen (2014) essa palavra é usada por diversas práticas devocionais e ritualísticas originadas a partir das escrituras védicas, significando simultaneamente "elevação" e "remoção daquilo que é mundano".

Dessa forma, considero que poderíamos melhor entender o sentido da palavra ao unirmos as duas possíveis traduções vendo um utsava (festival) como uma elevação promovida pela remoção daquilo que é mundano, ou seja, pela purificação. Podemos pensar o fenômeno não de maneira subjetiva, mas como um objetivo intercâmbio de substâncias concretas promovidas por um festival devocional Hare Krishna, sendo este um momento no qual as Deidades - através das linhas de associação traçadas pelo serviço - atraem pessoas para estarem em contato com elementos espiritualizados, devido ao fato de terem passado pelo procedimento de terem sido a elas oferecidos.

Tal como coloca Latour,

Sempre que um lugar intenta agir em outro, precisa atravessar transportando alguma coisa durante todo o percurso; para continuar agindo, precisa preservar algum tipo de conexão mais ou menos durável. (...) Os locais, agora transformados definitivamente em atores-rede, são movidos para o segundoplano; as conexões, veículos, e vínculos avançam para o primeiro plano (LATOUR, 2012, p.316). 
Para mapear essas conexões a partir de minha observação participante, imaginei como recurso reflexivo e narrativo um visitante hipotético adentrando o templo e participando do festival. Ao segui-lo no curso das associações que o levam e o integram no evento pude notar que a sequência de etapas da programação desse evento segue justamente o propósito de promover uma elevação (ou purificação) mediante contato da pessoa com determinados resíduos, objetos e pessoas consideradas, de acordo com o modo de ser do coletivo em questão, como sendo puras e assim capazes de purificar.

Buscando realizar a tarefa de aplainar o social em busca das redes de associações imaginei a seguinte situação: uma pessoa compra um livro ou recebe um convite, o que cria uma circunstância para que esta pessoa vá ao templo. Ali, em frente à porta do templo esta pessoa observa pinturas enquanto aguarda após ter tocado a campainha. Depois de entrar no templo e ser recebida por uma pessoa trajada em vestes exóticas com uma marca de argila na testa, sente de forma mais intensa o aroma de incenso, atravessa uma sala e é convidado a retirar os sapatos, antes de subir a escada e acessar a sala do altar, na qual se desenrola o programa.

No alto da escada, preso na parede ao lado esquerdo se encontra um sino. Mesmo que a pessoa não o toque, ela percebe que a maior parte das pessoas o soam ao passarem por ali, prestando reverências tocando a cabeça ao chão logo em seguida. A pessoa atravessa a sala e percebe, do lado direito, um altar com cortinas fechadas e, do lado esquerdo, a forma de um senhor moreno sob um assento de madeira almofadado.

Na primeira parte da programação a pessoa fica sentada no chão ouvindo e talvez cantando mantras (principalmente o Hare Krishna) acompanhada de instrumentos como a mrdanga, kartala e o harmonium. Ao término dessa etapa as pessoas são convidadas a ficarem de pé, para a adoração ao mestre espiritual (a forma morena percebida na entrada), homens do lado esquerdo (no piso inferior) e mulheres do lado direito (no piso superior). A pessoa então percebe que alguém colocou em frente da forma adorável do mestre um banco de madeira branco, sobre o qual estava um prato dourado contendo itens a serem ofertados: uma flor, um búzio, lenço, isqueiro e incenso. 
Depois ouve soar por três vezes o búzio e, enquanto as pessoas presentes cantam e dançam, cada um dos elementos é oferecido com sete voltas em direção ao mestre. Ao mesmo tempo em que oferece os elementos com a mão direita, o responsável pela oferenda faz soar um sino dourado com a mão esquerda.

Ao final da cantoria, marcada pelas reverências, a pessoa recebe pétalas para lançar sobre o quadrado de bronze com as marcas dos pés do mestre. Depois disso ouve uma palestra, entremeada por mantras. Mais uma vez se ouve o búzio, abrem-se as cortinas. Todos se lançam ao chão em reverência, as mulheres se prostrando e colocando a cabeça no chão e os homens se deitando na horizontal e esticando o corpo. Ao se levantar, esta pessoa vê no altar formas humanas em posição de dança, com cabelos longos, decorados com vestes coloridas, jóias e flores. Um deles tem a pele meio branca e rosada enquanto o outro apresenta uma tez dourada e brilhante. Mais uma vez são oferecidos com sete voltas no sentido horário - por um oficiante do ritual os elementos contidos no prato dourado, que, logo em seguida são respectivamente ofertados aos presentes enquanto estes cantam e dançam a canção e os mantras adequados para situação.

O canto termina, mais reverências. Um devoto passa um pequeno palito de algodão com essência aromática na mão direita da pessoa divina em forma de homemleão, depois no mestre e finalmente em cada um dos visitantes antes do último mantra. As cortinas se fecham. Após um pouco de espera, mais uma canção e finalmente, enquanto estão todos sentados no chão da sala do altar, é servido um jantar vegetariano (previamente oferecido às Deidades no altar), com direito a samosa, dahl, sabji, repetição, doce e suco natural. A pessoa então, depois de conversar um pouco enquanto 'tomava prasadam', volta pra casa ouvindo meio que constantemente reverberando no fundo da consciência o mantra Hare Krishna.

Seguindo esse visitante hipotético, criado a partir da descrição elaborada no tópico anterior, pude perceber que a relação com o festival pode ser dividida, buscando uma planificação dessa experiência, em sete etapas que terminam por encontrar sua culminância na abertura do altar, finalizando com a distribuição da prasadam (alimento vegetariano espiritualizado). Essas etapas foram esboçadas buscando aplainar a experiência de uma pessoa que chega, entra no templo (tal como colocada 
acima), com a própria programação do mesmo, dividido em bhajana (canto sentado), guru puja (adoração ao mestre espiritual), palestra, goura-aratik (abertura do altar) e jantar.

Em cada uma dessas etapas podemos notar objetos imbuídos de agência, os quais tanto trazem a pessoa para aquela possibilidade de associação como a conduzem, através das diferentes etapas, servindo como sinalizadores da transição de espaços. Além disso, alguns objetos, imantados pelo contato com pessoas consideradas transcendentais presentes nas formas adoráveis do mestre e das deidades, tornam-se resíduos espiritualizados e purificadores que contribuirão, na visão dos devotos, para o despertar espiritual da pessoa.

As sete etapas que configuram o movimento da pessoa ao longo de diferentes espaços e momentos rituais são: 1 - chegada (ou rua), 2 - recepção (entrada no templo), 3 - subida (na sala do altar para canto sentado), 4 - adoração ao mestre espiritual, 5 palestra, 6 - abertura do altar e 7 - jantar. Destas, as três primeiras são transições entre diferentes espaços, enquanto as quatro últimas são momentos rituais diferentes dentro do festival.

Desconsiderando casos específicos, o que em geral leva uma pessoa que está no espaço 1, ou seja, na rua, a vir associar-se com o templo e com os devotos é um convitinho, um livro ou o alimento espiritualizado. Elementos esses que podem ser considerados como actantes. Chegando em frente ao templo, ainda no espaço 1, a pessoa pode contemplar as pinturas e eventualmente já sentir os aromas de incenso e os sons dos mantras (os quais intensificam-se quando a pessoa passa do espaço 1 para o 2, adentrando o templo). A campainha (e também o livro ou convitinho que levaram ali) pode ser considerada como uma conexão entre a rua e a entrada do templo (espaço 2). O sino age como uma mediação entre a escada, vinda de baixo, e a sala do altar. $\mathrm{O}$ búzio, ao mesmo tempo em que dá início a uma nova etapa do festival, estabelece a possibilidade de comunicação com o mestre e com a Deidade.

Tal como coloca Latour

Por que não dizer que, em matéria de religião, só contam os seres capazes de levar pessoas a agir, como todo crente sempre afirmou? Isso seria mais empírico, talvez até mais científico, mais respeitoso e bem mais econômico do 
que inventar dois lugares impossíveis, irreais, onde a mente do religioso e a realidade social estivessem ocultas por trás de ilusões que muitas outras geraram (LATOUR, 2012, p. 336-337).

Para aprofundarmos a percepção do fenômeno, tendo em vista que ele visa produzir experiências, talvez fosse interessante coletar narrativas ligadas a essas vivências, de modo que fosse possível sobrepô-las às descrições das linhas de associação. Deixemos esta possibilidade como um fio a ser puxado, tendo em vista o caráter provisório e limitado do experimento aqui esboçado.

\section{Considerações finais}

Através do trabalho realizado pudemos averiguar a forma pela qual a TAR pode apresentar caminhos férteis para abordar reflexivamente experiências religiosas, tendo como ferramenta o conceito de rede de associações. Ao mesmo tempo em que conseguimos pensar sobre a experiência em questão sem nos valer de conceitos sobredeterminantes que tomam a prática como expressão de uma representação coletiva anterior, pudemos também, ao observar as associações que se estabelecem entre os actantes, nos referir a essas mediações tomando o pensamento nativo como uma orientação da prática e não como explicação dela.

A partir do experimento aqui realizado uma possível conclusão a que podemos chegar, ao analisar a experiência promovida pela rede em questão, é que na prática devocional analisada o som é, por excelência, um elemento que promove a intermediação entre os mundos, bem como entre os diferentes espaços e tempos rituais. Tudo aquilo que é oferecido a Krishna, presente na forma das Deidades, se transforma, segundo a perspectiva nativa, em um resíduo transcendental ao ser associado com o som transcendental (sabda brahman) capaz de promover purificação, ou seja, de desvincular a pessoa de associações ligadas ao mundo de fora (material e impuro) e conectá-la a associações centradas em Krishna (espiritual e transcendental).

É dessa forma que as Deidades e as linhas de serviço desdobradas pelo seu atendimento através de oferendas, cânticos e festivais levam as pessoas a agirem no sentido da própria realização concreta do sentindo mítico e profético de sua presença. 
Os mantras são a comunicação por excelência entre o transcendente e o imanente, entre o mundo espiritual e o mundo material, ou - melhor dizendo - quando o espiritual se faz presente na matéria ao tornar imanente o transcendental.

De acordo com Teoria do Ator Rede é justamente nessa associação constante entre os elementos da rede e nos híbridos que resultam dessas mediações que podemos encontrar os grupos constantemente se refazendo. Afinal não existem grupos, apenas processos de produção que resultam em estabilidades temporárias.

No pensamento Hare Krishna, a ideia de associação é também fundamental. $\mathrm{Na}$ comunidade que tomamos como unidade de análise, considera-se que, tendo em vista os ensinamentos de Prabhupada e escrituras como o Bhagavad-Gita e o Srimad Bhagavaram, o cultivo adequado da associação com os devotos, com o som do mantra e das escrituras tem o potencial de manifestar a consciência espiritual inerente que leva à auto-realização.

Essa concepção se expressa numa expressão comumente utilizada no dia a dia das comunidades. Sempre que se despedem entre si e também de visitantes eles dizem 'obrigado pela associação'. Ao considerarmos essas afirmações sobre a condição transcendental das associações e o poder purificador dos mantras, buscamos compreender a prática dos praticantes não como uma crença, mas como um conhecimento que ao orientar as associações realizadas no festival faz do próprio templo um tipo de laboratório em que se produzem as experiências coletivas que conferem fundamento para experiência da devoção

A crença, nessa perspectiva, é um conceito pouco útil, pois aparece como o modo pelo qual os modernos enquadram o conhecimento dos outros de forma a colocar sua própria forma de conhecer (ou de produzir híbridos) em um patamar privilegiado, ocupado por aqueles que se fundamentam em fatos (tomados como dados reais da natureza) e não em fetiches (tidos como criações ilusórias). Ao deixar de considerar as afirmações dos devotos a respeito das associações enquanto e crença, construindo esforços para entendê-las enquanto conhecimento, buscamos uma simetrização entre as perspectivas colocadas em relação.

A partir disso podemos nos perguntar quais as implicações de realidade contida nessas vivências? Se levarmos a sério a afirmação feita por parte dos devotos de 
que bhakti-yoga é uma ciência, se faz necessário questionar que tipo de ciência é essa ou em que sentido ela é, para seus praticantes, uma ciência. Mais ainda, tomando essa afirmação de forma simétrica podemos perguntar que mundos são esses que se manifestam através desta experiência

A devoção, assim como a ciência analisada por Latour (1997) em Vida de Laboratório, pode ser lida como um saber e um viver construído que depende de muitos atores. Em vez de um experimento - tornado objetivo por inscrições produzidas na interação entre cientistas, aparelhos, papéis, bactérias e neurônios - o serviço devocional (bhakti yoga) é, para estes Hare Krishnas, fundamentado na possibilidade de construção de uma experiência, possibilitada pela interação de devotos, instrumentos, Deidades, livros e oferendas.

Essa experiência é a inserção em redes heterogêneas que promovem as mediações e associações necessárias para produção da presença inerente à experiência do serviço devocional e ao engajamento a ele relacionado. É sob essa perspectiva que sugerimos que o templo pode ser visto como um laboratório, no qual se produzem as circunstâncias necessárias para a vivência da emoção devocional.

De forma alguma conseguimos aqui esgotar todas as possibilidades reflexivas que se apresentaram. Espero através das ideias acima elaboradas ter dado concretude à intuição de que o uso da teoria do ator rede como inspiração para produção de uma descrição etnográfica pode vir a ser útil no intuito de compreender como, através das redes híbridas, que misturam a rua e o templo, o mundo espiritual e o mundo material, são produzidas as emoções que subjazem o processo de engajamento no serviço devocional.

Cabe colocar que tanto no que se refere ao potencial descritivo da teoria do ator rede quanto à fertilidade etnográfica da situação analisada, muito ainda poderá ser dito. Como um experimento, esse texto é somente uma das muitas versões possíveis desse entrelaçamento, uma mediação entre minha experiência de pesquisador e a do leitor que agora lê estas palavras.

Dessa maneira considero que a apropriação teórica aqui realizada não se deve a um esforço de tentar encontrar um exemplar demonstrativo de uma teoria em voga, mas sim de considerar que a realização de um experimento reflexivo nesses moldes 
pode vir a ser uma ferramenta útil ao oferecer legibilidade e compreensão (a partir de um ponto de vista diferente daquele oferecido pela teoria nativa) ao modo pelo qual estes devotos argumentam sobre a realidade transcendental de suas práticas.

\section{Referências}

ELIAS, Norbert (1994). Sociedade dos indivíduos. São Paulo: Edusp.

FLOOD, Gavin (2015). Introdução ao Hinduísmo. Juiz de Fora: UFJF.

GONZALES, Zuleika Kohler; BAUM, Carlos (2013) Desdobrado a teoria do ator rede: Reagregando o social no trabalho de Bruno Latour. Polis e Psique, Porto Alegre, v. 3, n . 1, p.142-157.

LATOUR, Bruno. (2004). "Não congelarás a imagem”, ou: como não desentender o debate ciência-religião. Mana, Rio de Janeiro, v.10, n.2, p.349-375.

(2010). Jamais fomos modernos: ensaios de uma antropologia simétrica. Rio de Janeiro: Ed. 34.

. (2012). Reagregando o social: uma introdução à teoria do ator-rede. Trad. Gilson César Cardoso de Sousa. Salvador/Bauru: Edufba/Edusc.

PRABHUPADA, A. C. Bhaktivedanta Swami (1975). Srimad Bhagavatam: Sétimo Canto. BBT: São Paulo. 